Check for updates

Cite this: RSC Adv., 2018, 8, 7988

Received 14th January 2018 Accepted 3rd February 2018

DOI: $10.1039 / \mathrm{c} 8 \mathrm{ra00411k}$

rsc.li/rsc-advances

\section{Theoretical study of the oxidation reactions of sulfurous acid/sulfite with ozone to produce sulfuric acid/sulfate with atmospheric implications $\dagger$}

\author{
Fang Sheng, ${ }^{a}$ Liu Jingjing, ${ }^{\star b}$ Chen $Y u^{a}{ }^{a}$ Tao Fu-Ming, ${ }^{c}$ Duan Xuemei ${ }^{\star a}$ \\ and Liu Jing-yao (DD ${ }^{a}$
}

Herein, theoretical studies were performed on the atmospheric oxidation of sulfurous acid $\left(\mathrm{H}_{2} \mathrm{SO}_{3}\right)$ and sulfite ions $\left(\mathrm{HSO}_{3}{ }^{-}\right)$by ozone $\left(\mathrm{O}_{3}\right)$ to produce sulfuric acid and hydrosulfate ions. The most favorable path for the $\mathrm{H}_{2} \mathrm{SO}_{3}+\mathrm{O}_{3}$ reaction has been found to be initiated from concerted $\mathrm{H}$-abstraction and oxygen addition, with an overall energy barrier of $18.3 \mathrm{kcal} \mathrm{mol}^{-1}$. On the other hand, the most favorable path for the $\mathrm{HSO}_{3}{ }^{-}+\mathrm{O}_{3}$ reaction is initiated from oxygen addition, with an overall energy barrier of only $0.3 \mathrm{kcal} \mathrm{mol}^{-1}$. Kinetic simulations were performed to estimate the significance of these reactions in the formation of atmospheric sulfate and destruction of the ozone layer. The results provide new insight into the missing source of atmospheric sulfate and particulate matter

\section{Introduction}

Oxidation reactions are the most important reactions in the atmosphere, which connect anthropogenic and natural species. ${ }^{\mathbf{1 , 2}}$ The oxidation of sulfur species is considered to be the main channel for the production of atmospheric sulfuric acid $\left(\mathrm{H}_{2} \mathrm{SO}_{4}\right)$ or sulfate species. ${ }^{3,4}$ Gaseous sulfuric acid and sulfate have been identified as the major drivers to generate atmospheric aerosols. ${ }^{3,5-7}$ As is well known, aerosols have a significant impact on the global environment such as climate change, reduction in visibility, and public health effects. ${ }^{8}$ In addition, hexavalent sulfur species are confirmed as the major fraction of PM2.5 (aerosol particles with an aerodynamic diameter less than $2.5 \mu \mathrm{m}$ ), which are associated with certain sicknesses and other acute or chronic health effects. ${ }^{7}$ Air pollution caused by sulfur emissions will remain for a long time in China due to its coal-based energy structure. ${ }^{9}$ Haze days with high concentrations of PM2.5 appear frequently in the northern cities of China during the cold winter and spring seasons ${ }^{\mathbf{1 0}}$ due to the increase in emissions from heating. ${ }^{\mathbf{1 1 , 1 2}}$ Atmospheric aerosols are hazardous to both human health and the environment., ${ }^{3,7}$ Therefore, understanding the

${ }^{a}$ Institute of Theoretical Chemistry, Laboratory of Theoretical and Computational Chemistry, Jilin University, Changchun 130023, China. E-mail: duanxm@jlu.edu.cn ${ }^{b}$ Department of Chemistry, Key Laboratory of Organic Optoelectronics \& Molecular Engineering of Ministry of Education, Tsinghua University, Beijing 100084, China. E-mail: enouragement@mail.tsinghua.edu.cn

${ }^{c}$ Department of Chemistry and Biochemistry, California State University, Fullerton, California 92834, USA

$\dagger$ Electronic supplementary information (ESI) available. See DOI: 10.1039/c8ra00411k formation process of sulfuric acid or sulfate species is a critical step in developing the atmospheric sulfur cycle.

The oxidation of sulfur dioxide $\left(\mathrm{SO}_{2}\right)$ is known as the main source of atmospheric sulfate..$^{4,13-15}$ The oxidation reactions of $\mathrm{SO}_{2}$ have been extensively studied in a variety of experimental approaches and theoretical calculations., ${ }^{\mathbf{1 2 - 1 4 , 1 6 - 2 7}}$ Several reaction mechanisms have been proposed, ranging from gas-phase oxidation by atmospheric radicals (Criegee intermediate (6,17,25-27 $^{\mathbf{1}}$ and hydroxyl ${ }^{4,13,14}$ and hydroperoxy radicals ${ }^{18}$ ) to aqueous-phase reaction by $\mathrm{O}_{3},{ }^{20,24,28}$ hydrogen peroxide, ${ }^{29}$ and others. ${ }^{30}$ To date, a consensus has emerged that the production of gaseous sulfate is determined by the $\mathrm{SO}_{2}+\mathrm{OH}$ reaction. ${ }^{30}$ However, recent studies have shown that the formation of sulfate from traditional air quality models does not account for the high sulfate levels observed; this suggests the existence of missing pathways for sulfate production. ${ }^{31,32}$ Thus, new reaction pathways should be explored for the formation of atmospheric sulfate.

New models have been recently proposed for the formation of sulfate in the troposphere, clouds, aerosols, acid rain, and fog to bridge the gap between the modeled and observed sulfate. ${ }^{20,32-35} \mathrm{SO}_{2}$ can be quickly taken into fog and rain droplets, ${ }^{36}$ which is followed by its liquid phase oxidation by $\mathrm{O}_{3}$ and $\mathrm{H}_{2} \mathrm{O}_{2} \cdot{ }^{20,24,28,29,37,38}$ Model studies suggest that the oxidation of $\mathrm{SO}_{2}$ in the aqueous phase results in more than $80 \%$ of the global sulfate production. ${ }^{39}$ In some of these models, the hydrolysis reaction of $\mathrm{SO}_{2}$ plays an important role, and bisulfite anion $\left(\mathrm{HSO}_{3}{ }^{-}\right)$serves as a product of hydrolysis, which is one of the dominant sulfur(Iv) species. ${ }^{40}$ The extensive vibrational spectroscopy studies conducted by Simon and Waldman revealed the presence of bisulfite anion $\left(\mathrm{HSO}_{3}{ }^{-}\right)$, which resulted from 
the dissolution of $\mathrm{SO}_{2}$ in water. ${ }^{\mathbf{4 1 - 4 5}}$ In addition, it has been proven that the existence of $\mathrm{NH}_{3}$ in hydrated $\mathrm{SO}_{2}$ clusters accelerates the production of $\mathrm{HSO}_{3}{ }^{-} ;^{33}$ moreover, the rate of oxidation of dissolved $\mathrm{SO}_{2}$ by $\mathrm{O}_{3}$ to form sulfate is enhanced. ${ }^{46}$ As another product of hydrolysis, sulfurous acid $\left(\mathrm{H}_{2} \mathrm{SO}_{3}\right)$ was first generated in an experiment conducted by Schwarz et al. in 1988 and was considered stable in the gas phase. ${ }^{47}$ Recent studies have shown that $\mathrm{SO}_{2}$ can hydrolyze to produce sulfurous acid $\left(\mathrm{H}_{2} \mathrm{SO}_{3}\right)$ or $\mathrm{HSO}_{3}{ }^{-}$in the gas phase in the presence of acid molecules or clusters such as water, hydrated ammonia, and hydrated sulfuric acid clusters. ${ }^{33,34}$ In addition, sulfurous acid and bisulfite were thought to be potential precursors for the formation of atmospheric aerosols. However, to the best of our knowledge, no studies have been reported on the atmospheric oxidation of $\mathrm{H}_{2} \mathrm{SO}_{3} / \mathrm{HSO}_{3}{ }^{-}$to produce $\mathrm{H}_{2} \mathrm{SO}_{4} / \mathrm{HSO}_{4}{ }^{-}$.

$\mathrm{O}_{3}$ is a reactive oxidant in natural and polluted tropospheres. ${ }^{48}$ It also acts as an oxidant in the aqueous oxidation of $\mathrm{SO}_{2}$ (ref. 24) together with transition metal ion catalysts $\left(\mathrm{Co}^{2+}\right.$, $\mathrm{Fe}^{3+}$, and $\left.\mathrm{Mn}^{2+}\right) .^{\mathbf{2 0 , 4 0}}$ Furthermore, the gas-phase oxidation of $\mathrm{SO}_{2}$ by $\mathrm{O}_{3}$ is known to have minor contributions to atmospheric sulfate formation due to its relatively high energy barrier and small rate constant. ${ }^{49}$ However, Cheng et al. have reported that the concentrations of $\mathrm{O}_{3}$ drop dramatically during the haze period together with an increase in sulfate production; this suggests new possible pathways for the formation of sulfate in the presence of $\mathrm{O}_{3} \cdot{ }^{32}$ Consequently, we carried out a detailed theoretical investigation on the reaction mechanism of $\mathrm{H}_{2} \mathrm{SO}_{3} /$ $\mathrm{HSO}_{3}{ }^{-}+\mathrm{O}_{3}$. To further evaluate the atmospheric implications of the title reactions, the rate constants were calculated utilizing the transition state theory. Our results will provide potential insights into the new mechanisms for atmospheric sulfate generation.

\section{Computational methods}

The structures of the reactants, intermediates, transition states, and products were optimized by the M06-2X functional (density functional theory $)^{50}$ combined with the $6-311++\mathrm{G}(3 \mathrm{df}, 3 \mathrm{pd})$ basis set using the Gaussian 09 program. ${ }^{51}$ The M06-2X method has been widely used in the computation of atmospheric reactions and proven to provide reliable results. ${ }^{52-56}$ Harmonic vibrational analyses were conducted to provide the zero-point energy (ZPE) corrections as well as to confirm the minima character of the obtained geometries at the same level of theory (i.e. the local minimal with positive frequencies and saddle points with only one imaginary frequency). The ZPE corrections were included in the determination of relative energy for each stationary point. Intrinsic reaction coordinate (IRC) calculations were performed to confirm that the transition states corresponded to the designated reactants and products. To obtain more accurate energetic information, single point energy calculations were carried out at the $\operatorname{CCSD}(\mathrm{T})$ /aug-cc-pVTZ level of theory.

Due to the partial biradical character of $\mathrm{O}_{3},{ }^{57}$ the reliability of the results obtained had to be determined from the singlereference-based coupled-cluster wave function $(\operatorname{CCSD}(\mathrm{T}))$; one of the best methods to determine this is through the $T_{1}$ diagnostic. $^{58}$

$$
T_{1}=\left\|t_{1}\right\| /(N)_{\mathrm{elec}}^{1 / 2}
$$

where $\left\|t_{1}\right\|$ is the Euclidean norm of the $t_{1}$ vector of the coupledcluster wave function, and it is divided by the square root of the number of correlated electrons to normalize $T_{1}$. It is recommended that $T_{1}$ diagnostic values below 0.045 are acceptable. ${ }^{59}$ All the values of $T_{1}$ typically cover the range of $0.0015-0.035$ (except for TS16-P), and most of them are lower than 0.025 (see Table $\mathrm{S} 1 \dagger)$. This means that almost all the stationary points have very small multi-reference character, and $\operatorname{CCSD}(\mathrm{T}) /$ aug-ccpVTZ could sufficiently describe the electronic states and provide reasonable energies. ${ }^{23}$ For TS16-P, the $T_{1}$ diagnostic value is 0.068 , indicating that the single-reference-based coupled-cluster method is inadequate to calculate the energies and the multi-reference method is needed to provide a more reliable energy barrier of the transition state TS16-P. Therefore, the complete active space self-consistent field (CASSCF) theory (multi-reference method) was chosen to obtain the reference wave functions of In16 and TS16-P. ${ }^{60}$ Taking into account the dynamic correlation effects, the single point energies of these two stationary points were further refined using the second-order multi-configuration CASPT2 method. The CASPT2//CASSCF calculations were performed using the MOLPRO quantum chemistry package. ${ }^{61}$

\section{Results and discussion}

\subsection{Mechanism of the $\mathrm{H}_{2} \mathrm{SO}_{3}+\mathrm{O}_{3}$ reaction}

Due to the multiple reaction sites in $\mathrm{H}_{2} \mathrm{SO}_{3}$ and $\mathrm{O}_{3}$, there are five reaction pathways (paths 1-5) according to the different entrance channels. As shown in Fig. 1, in path 1, path 2, and path 5 , the reactions start with the collision of the reactants; this leads to the formation of the hydrogen-bond intermediates Int1, Int5, and Int16, respectively. In paths 3 and 4, the reactions initiate from the cycloaddition reaction processes. The detailed reaction pathways with lower energy barriers as well as the geometrical structures of the stationary points are displayed in Fig. 2-4. The other reaction pathways with much higher energy barriers are presented in the ESI (Fig. S1 and S2 $\dagger$ ).

3.1.1 Reaction starting from Int1 (path 1). For path 1, the reaction is initiated from the intermediate Int1 formed by one of the terminal oxygen atoms (O9) in $\mathrm{O}_{3}$ approaching one

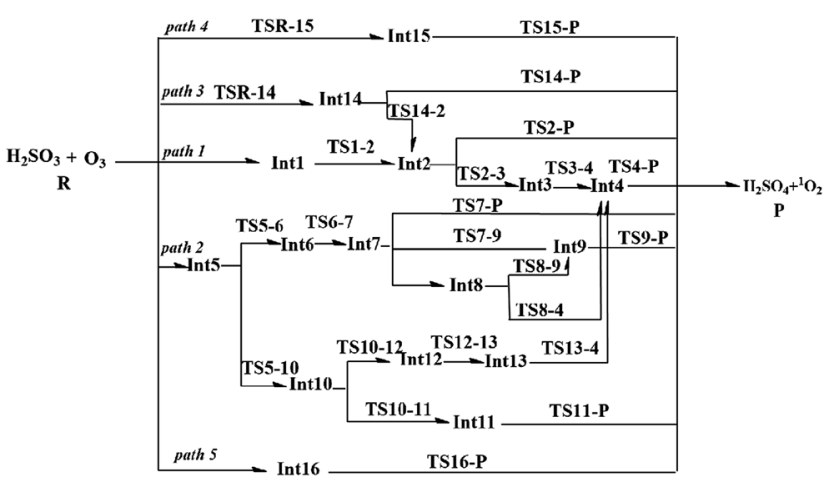

Fig. 1 Possible reaction pathways for the $\mathrm{H}_{2} \mathrm{SO}_{3}+\mathrm{O}_{3}$ reaction. 


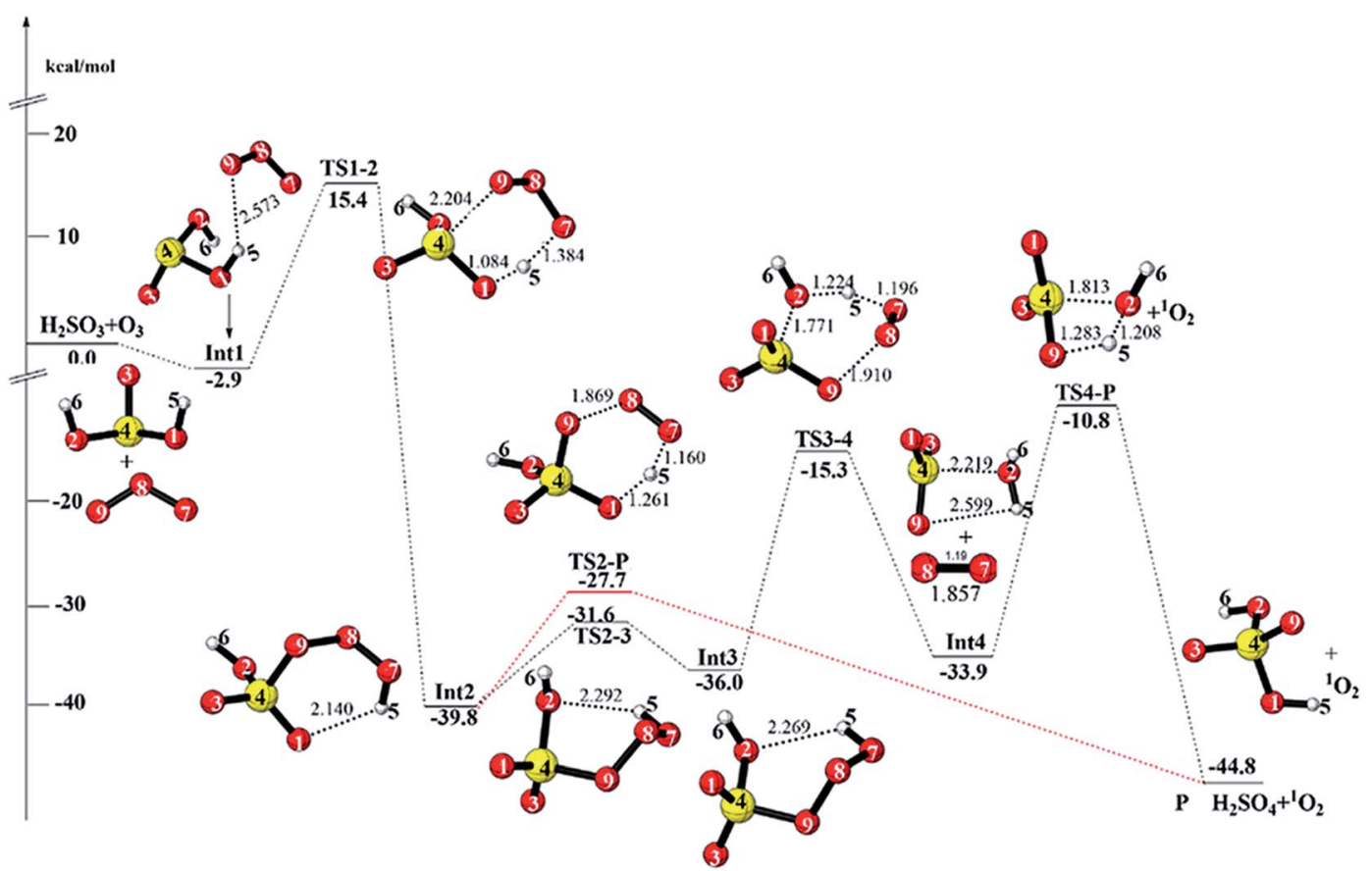

Fig. $2 \mathrm{CCSD}(\mathrm{T}) /$ aug-cc-pVTZ//M06-2X/6-311++G(3df,3pd) + ZPE energy profile and the optimized geometries of the stationary points for the reaction of $\mathrm{H}_{2} \mathrm{SO}_{3}+\mathrm{O}_{3}$ (distances are in angstroms).

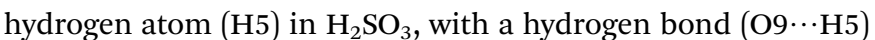
distance of $2.573 \AA$. This weak intermolecular hydrogen bond leads to an energy decrease of $2.9 \mathrm{kcal} \mathrm{mol}^{-1}$ relative to that of the initial reactants. Subsequently, the reaction proceeds to produce the intermediate Int2 via the concerted transition state TS1-2 with the energy barrier of $18.3 \mathrm{kcal} \mathrm{mol}^{-1}$. In TS1-2, one

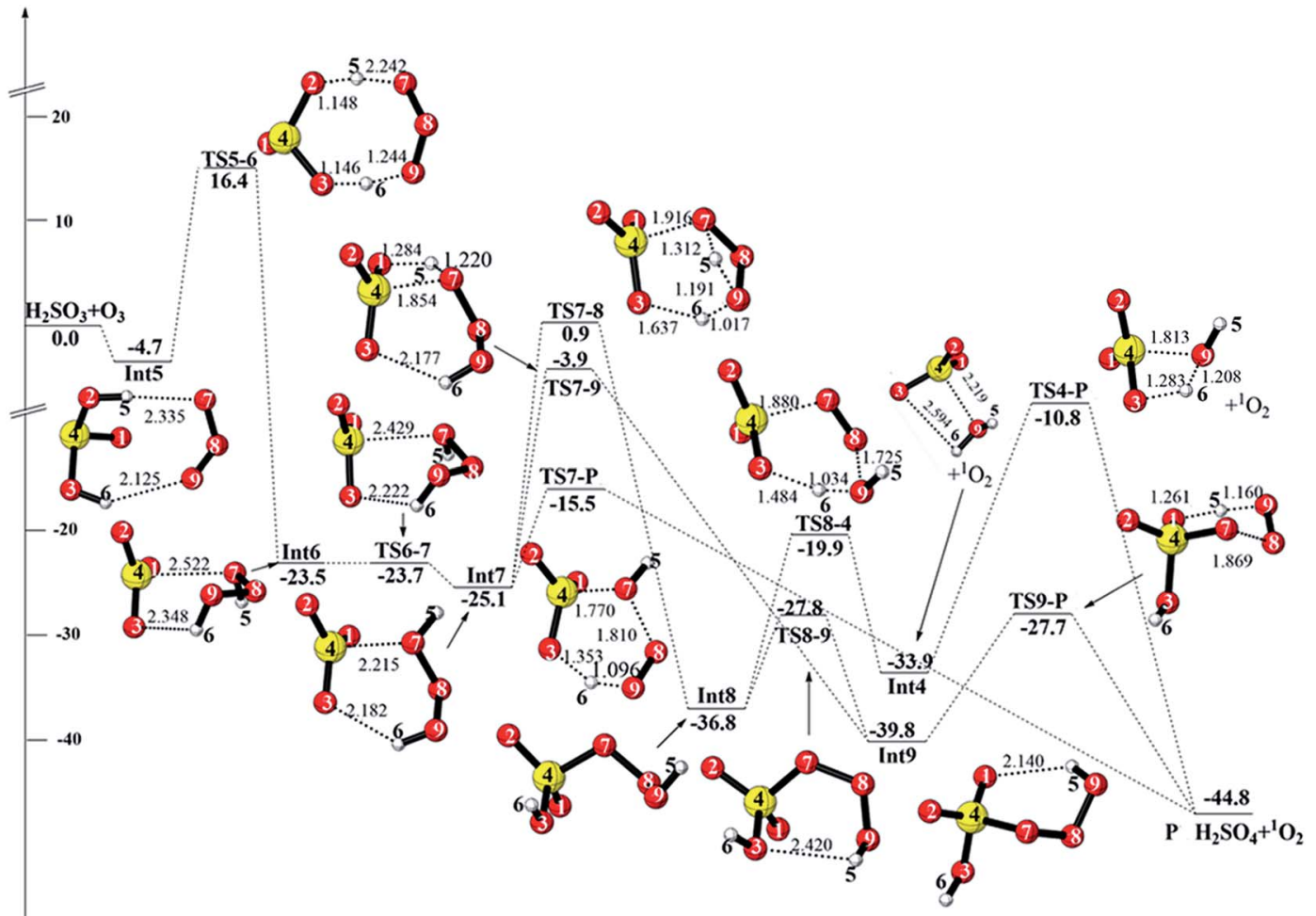

Fig. $3 \mathrm{CCSD}(\mathrm{T}) /$ aug-cc-pVTZ//M06-2X/6-311++G(3df,3pd) + ZPE energy profile and the optimized geometries of the stationary points for the reaction of $\mathrm{H}_{2} \mathrm{SO}_{3}+\mathrm{O}_{3}$ (distances are in angstroms). 


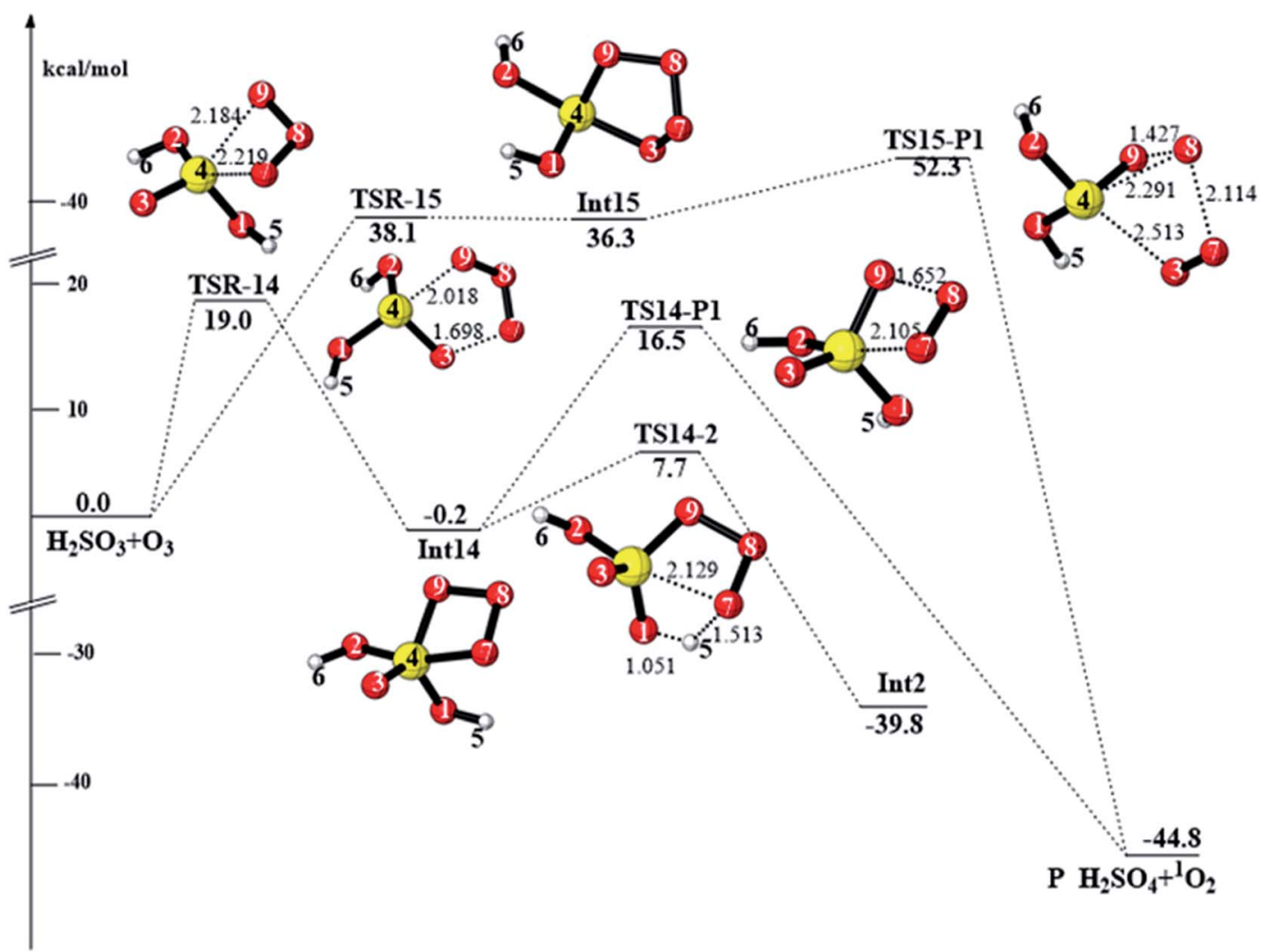

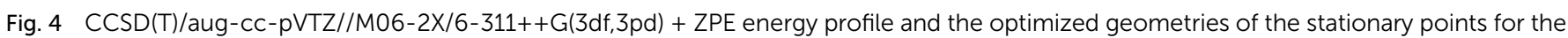
reaction of $\mathrm{H}_{2} \mathrm{SO}_{3}+\mathrm{O}_{3}$ (distances are in angstroms).

terminal oxygen atom (O9) in $\mathrm{O}_{3}$ adds to sulfur atom, and the other terminal oxygen atom $(\mathrm{O} 7)$ of $\mathrm{O}_{3}$ abstracts $\mathrm{H} 5$ atom from $\mathrm{H}_{2} \mathrm{SO}_{3}$ simultaneously. The intramolecular hydrogen bond $(\mathrm{O} 1 \cdots \mathrm{H} 5)$ leads to the six-membered ring structure of Int2, which is $-39.8 \mathrm{kcal} \mathrm{mol}^{-1}$ lower than the reactants. From Int2, there are two possible reaction pathways, as shown in Fig. 2. For one pathway, Int2 decomposes directly to generate the final products $\mathbf{P}\left(\mathrm{H}_{2} \mathrm{SO}_{4}\right.$ and singlet $\left.\mathrm{O}_{2}\right)$ through the transition state TS2-P, in which cleavage of the O8-O9 bond and transfer of $\mathrm{H} 5$ from $\mathrm{O} 7$ to $\mathrm{O} 1$ take place simultaneously with an energy barrier of $12.1 \mathrm{kcal} \mathrm{mol}^{-1}$. The large energy release $\left(44.8 \mathrm{kcal} \mathrm{mol}^{-1}\right)$ from the initial reactants to the products indicates the thermodynamic feasibility of the $\mathrm{H}_{2} \mathrm{SO}_{3}+\mathrm{O}_{3}$ reaction.

For the second pathway, Int2 undergoes an isomerization process to form Int3 via the rotation of the dihedral angle O8O9-S-O2 (TS2-3), and the energy barrier is $8.2 \mathrm{kcal} \mathrm{mol}^{-1}$. This rotation of the dihedral angle leads to distortion of the sixmembered ring; accordingly, Int 3 is less stable than Int 2 by $3.8 \mathrm{kcal} \mathrm{mol}{ }^{-1}$. Then, Int3 decomposes to produce monohydrated sulfur trioxide and ${ }^{1} \mathrm{O}_{2}$ via the transition state TS3-4, in which the cleavage of $\mathrm{O} 8-\mathrm{O} 9$ bond and transfer of $\mathrm{H} 5$ from O7 to $\mathrm{O} 2$ take place simultaneously. The energy barrier of TS3-4 is $20.7 \mathrm{kcal} \mathrm{mol}^{-1}$. The hydrated sulfur trioxide can hydrolyze to form sulfuric acid via a four-membered proton transfer transition state (TS4-P) with an energy barrier of $23.1 \mathrm{kcal} \mathrm{mol}^{-1}$. Although the energy barrier of the $\mathrm{SO}_{3}$ hydrolysis reaction is slightly high, this reaction has been proven to be a catalytic reaction, and the energy barrier becomes evidently low or nearly disappears when water molecules or atmospheric acids act as catalysts in the hydrolysis reaction. ${ }^{62}$ Therefore, this reaction pathway will be increasingly important together with the environmental conditions such as high humidity or haze. Thus, the oxidation of $\mathrm{H}_{2} \mathrm{SO}_{3}$ by $\mathrm{O}_{3}$ starting from Int1 mainly occurs via the pathway reactants $\rightarrow$ Int1 $\rightarrow$ Int $2 \rightarrow \mathbf{P}$ with the overall energy barrier of $18.3 \mathrm{kcal} \mathrm{mol}^{-1}$.

3.1.2 Reaction initiating from Int5 (path 2). When two terminal oxygen atoms of $\mathrm{O}_{3}$ approach two hydrogen atoms of $\mathrm{H}_{2} \mathrm{SO}_{3}$, the hydrogen-bonded intermediate Int5 forms, with the hydrogen bond lengths of 2.335 and $2.125 \AA$. Int5 is lower in energy by $4.7 \mathrm{kcal} \mathrm{mol}^{-1}$ relative to the reactants. As shown in Fig. 1, there are two channels followed by Int5. We have only discussed the more feasible reactions depicted in Fig. 3. Int5 can isomerize to produce Int6 via the double $\mathrm{H}$-abstraction transition state TS5-6. This process needs to overcome an energy barrier of $21.1 \mathrm{kcal} \mathrm{mol}^{-1}$. In Int6, hydrogen trioxide $\left(\mathrm{H}_{2} \mathrm{O}_{3}\right)$ interacts with $\mathrm{SO}_{3}$ by an intermolecular van der Waals interaction $(2.552 \AA)$ and a hydrogen bond $(2.348 \AA$ ). The torsion of the O7-O8-O9-H6 dihedral angle in Int6 leads to the intermediate Int7 via the barrierless transition state TS6-7. There are three channels followed by Int7. First, an analogous hydrolysis reaction takes place to produce $\mathbf{P}$ via the transition state TS7-P. In TS7-P, the proton transfers from $\mathrm{O} 9$ to $\mathrm{O} 3, \mathrm{O} 7$ adds to an $\mathrm{S}$ atom, and simultaneously, the $\mathrm{O} 7-\mathrm{O} 8$ bond is broken. The 
energy barrier and energy release of this elementary reaction is 9.6 and $19.7 \mathrm{kcal} \mathrm{mol}^{-1}$, respectively.

With respect to the second reaction channels, Int7 undergoes a rearrangement process to produce Int8, which needs to pass through the transition state TS7-8 with an energy barrier of $26.0 \mathrm{kcal} \mathrm{mol}^{-1}$. In TS7-8, $\mathrm{H} 5$ transfers from $\mathrm{O} 7$ to $\mathrm{O} 9$, $\mathrm{H} 6$ transfers from $\mathrm{O} 9$ to $\mathrm{O} 3$, and simultaneously, $\mathrm{O} 7$ adds to the $\mathrm{S}$ atom. Once Int8 is formed, there are two possible pathways connecting to $\mathbf{P}$. For one pathway, Int8 undergoes an isomerization process (TS8-9), yielding the intermediate Int9. The energy barrier of this isomerization process is $9.0 \mathrm{kcal} \mathrm{mol}^{-1}$. Then, proton transfer and $\mathrm{O} 7-\mathrm{O} 8$ bond cleavage take place simultaneously via the transition state TS9-P to generate $\mathbf{P}$. Otherwise, Int8 can connect to Int4 via the concerted transition state TS8-4 with an energy barrier of $16.9 \mathrm{kcal} \mathrm{mol}^{-1}$, and the following reaction pathways are the same as those in path 1 . With regard to the third reaction channel initiating from Int7, it proceeds to produce Int9 via the transition state TS7-9. The computed energy barrier of TS7-9 is $21.2 \mathrm{kcal} \mathrm{mol}^{-1}$.

On the other hand, Int5 can also isomerize to produce Int10 via the seven-membered ring transition state TS5-10. Following Int10, the reaction proceeds to produce Int11, which finally decomposes to produce $\mathrm{H}_{2} \mathrm{SO}_{4}+{ }^{1} \mathrm{O}_{2}$ via TS11-P (see Fig. S1†). The energy barrier of this reaction path is as high as $35.7 \mathrm{kcal} \mathrm{mol}^{-1}$. In addition, Int10 can connect to Int4 via a continuous isomerization reaction process. These reaction pathways are not competitive due to their high energy barriers, and the details of these reaction pathways are presented in the ESI (see Fig. S1†). To summarize, among all the pathways discussed in this section, the reaction path: reactants $\rightarrow$ Int5 $\rightarrow$ Int6 $\rightarrow$ Int $7 \rightarrow \mathbf{P}$ is the most favorable with the total energy barrier of $21.1 \mathrm{kcal} \mathrm{mol}^{-1}$.

3.1.3 Reactions initiating from Int14, Int15, and Int16 (path 3, path 4, and path 5). When two terminal oxygen atoms in $\mathrm{O}_{3}$ add to the $\mathrm{S}$ atom, the cycloaddition product Int14 is formed. The energy barrier (TSR-14) of this cycloaddition process is $19.0 \mathrm{kcal} \mathrm{mol}^{-1}$. As shown in Fig. 4, there are two further reaction channels initiating from Int14. For the first reaction channel, Int14 decomposes to the products via the transition state TS14-P with the rupture of the $\mathrm{O} 7-\mathrm{S}$ and $\mathrm{O} 8-\mathrm{O} 9$ bonds. The energy barrier of this transition state is $16.7 \mathrm{kcal} \mathrm{mol}^{-1}$. For the second reaction channel, Int14 connects to Int2 via the transition state TS14-2, in which the $\mathrm{S}-\mathrm{O} 7$ bond ruptures, and simultaneously, $\mathrm{H} 5$ transfers from $\mathrm{O} 1$ to $\mathrm{O} 7$. This process needs to pass through an energy barrier of $7.9 \mathrm{kcal} \mathrm{mol}^{-1}$. Followed by Int2, the reaction is the same as that in path 1.

The terminal oxygen atoms in $\mathrm{O}_{3}$ can also add to the $\mathrm{S}=\mathrm{O}$ bond; this yields the five-membered structure Int15 (path 4). Then, Int15 dissociates to produce $\mathbf{P}$ via TSR-15, with an energy barrier (TSR-15) of $52.3 \mathrm{kcal} \mathrm{mol}^{-1}$. Thus, this reaction channel is not competitive.

For path 5, the reaction initiates from the hydrogen-bonded intermediate Int16, which is followed by oxygen addition via the transition state TS16-P to produce $\mathrm{H}_{2} \mathrm{SO}_{4}+{ }^{1} \mathrm{O}_{2}$. The energy barrier of TS16-P is $29.1 \mathrm{kcal} \mathrm{mol}^{-1}$ at the CCSD(T)/aug-cc-pVTZ level. However, the $T_{1}$ diagnostic value of TS16-P is 0.068 . Therefore, the CASPT2//CASSCF/aug-cc-pVTZ method was employed to further verify the energy barrier of TS16-P, and the computed energy barrier of TS16-P was $44.1 \mathrm{kcal} \mathrm{mol}^{-1}$ (see Fig. S2 $\dagger$ ). This further confirms that this reaction channel is kinetically unfavorable. To conclude, among the reactions discussed in this section, the reaction pathway reactants $\rightarrow$ Int14 $\rightarrow \mathbf{P}$ is the most feasible with the total energy barrier of $19.0 \mathrm{kcal} \mathrm{mol}^{-1}$.

\subsection{Mechanism of the $\mathrm{HSO}_{3}{ }^{-}+\mathrm{O}_{3}$ reaction}

As discussed in the introduction, $\mathrm{SO}_{2}$ can easily hydrolyze to produce bisulfite in the gas phase, and the detailed mechanisms for the oxidation of $\mathrm{HSO}_{3}{ }^{-}$by $\mathrm{O}_{3}$ are presented in Fig. 5 . The intramolecular interaction of $\mathrm{HSO}_{3}{ }^{-}$and $\mathrm{O}_{3}$ leads to the formation of the intermediate Int1 ${ }^{\prime}$ with the binding energy of $4.6 \mathrm{kcal} \mathrm{mol}^{-1}$ and then Int1 $^{\prime}$ decomposes to the bisulfate ion $\left(\mathrm{HSO}_{4}{ }^{-}\right)$and ${ }^{1} \mathrm{O}_{2}$ products via the transition state TS1- $\mathbf{P}^{\prime}$. In TS1$\mathbf{P}^{\prime}$, O6 adds to the sulfur atom, and simultaneously, the O6-O7 bond breaks. The barrier height of this process is only $0.3 \mathrm{kcal} \mathrm{mol}^{-1}$. The reaction is exothermic by as much as $60.4 \mathrm{kcal} \mathrm{mol}^{-1}$.

The intermediate Int1 ${ }^{\prime}$ can connect to Int2' via the transition state TS1-2' . Similar to TS1-2, H5-abstraction and oxygen addition take place simultaneously in TS1-2'. The energy barrier of TS1-2' is $0.3 \mathrm{kcal} \mathrm{mol}^{-1}$ relative to that of Int1' ${ }^{\prime}$. Then, the reaction proceeds by the concerted transfer of $\mathrm{H} 5$ from $\mathrm{O} 8$ to $\mathrm{O} 1$ and $06-\mathrm{O} 7$ bond cleavage via the transition state $\mathbf{T S 2}-\mathbf{P}^{\prime}$ to produce the terminal products $\mathbf{P}^{\prime}\left(\mathrm{HSO}_{4}{ }^{-}+{ }^{1} \mathrm{O}_{2}\right)$. The energy barrier of TS2-P' is $11.9 \mathrm{kcal} \mathrm{mol}^{-1}$.

In addition, the cycloaddition reaction can take place either by the transition state TSR-6 $^{\prime}$ or TS3-4' to form the fivemembered ring intermediate Int6 ${ }^{\prime}$ or seven-membered ring intermediate Int4', respectively. These two cycloaddition reactions are similar to the reaction processes via the transition states TSR-15 and TS5-10 (Fig. S2 $\dagger$ ). Int6' decomposes into $\mathrm{HSO}_{4}{ }^{-}$and ${ }^{1} \mathrm{O}_{2}$ by O-O bond cleavage via the transition state TS6-P' ${ }^{\prime}$. Int $4^{\prime}$ can connect to Int $2^{\prime}$ via a continuous isomerization reaction via TS4-5' and TS5-2' and then decompose to $\mathrm{HSO}_{4}{ }^{-}$ and ${ }^{1} \mathrm{O}_{2}$ via the transition state TS2-P'. However, the two reaction pathways discussed in this section are not competitive due to their relatively high energy barriers $(23.1$ and $28.0 \mathrm{kcal} \mathrm{mol}^{-1}$ ). Therefore, among the reactions of $\mathrm{HSO}_{3}{ }^{-}+\mathrm{O}_{3}$, the reaction pathway reactant $\left(\mathbf{H S O}_{3}{ }^{-}+\mathbf{O}_{3}\right) \rightarrow$ Int1 $^{\prime} \rightarrow$ TS1-P' $\rightarrow \mathbf{P}^{\prime}\left(\mathbf{H S O}_{4}{ }^{-}+{ }^{1} \mathbf{O}_{2}\right)$ is the most feasible with the total energy barrier of only $0.3 \mathrm{kcal} \mathrm{mol}^{-1}$.

\subsection{Comparison of the molecular orbitals of the intermediates}

When a $\mathrm{H}_{2} \mathrm{SO}_{3}$ molecule dissociates one proton forming the $\mathrm{HSO}_{3}{ }^{-}$anion, the reaction mechanisms are entirely different. Oxygen addition from $\mathrm{Int1}^{\prime}$ in the $\mathrm{HSO}_{3}{ }^{-}+\mathrm{O}_{3}$ reaction is the most favorable reaction pathway with an energy barrier of only $0.3 \mathrm{kcal} \mathrm{mol}^{-1}$ (Fig. 5), whereas the similar reaction path from Int16 in the $\mathrm{H}_{2} \mathrm{SO}_{3}+\mathrm{O}_{3}$ reaction is unfeasible due to is high energy barrier of over $29 \mathrm{kcal} \mathrm{mol}^{-1}$ (see Fig. S2 $\dagger$ ). To further explain the huge differences in the energy barriers of these two reaction channels, the molecular orbital analysis is a good 


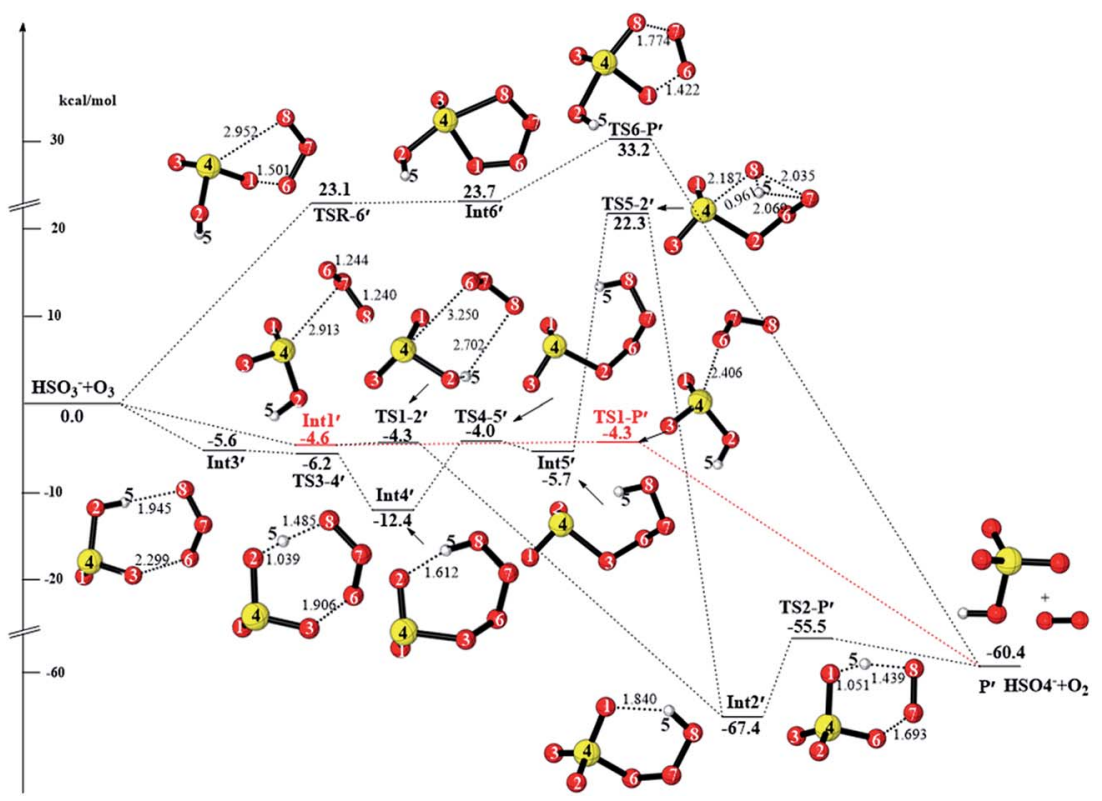

Fig. $5 \mathrm{CCSD}(\mathrm{T}) /$ aug-cc-pVTZ//M06-2X/6-311++G(3df,3pd) + ZPE energy profile and the optimized geometries of the stationary points for the reaction of $\mathrm{HSO}_{3}^{-}+\mathrm{O}_{3}$ (distances are in angstroms).

choice. It is generally recognized that the kinetic stability of reactants or reactant intermediates can be quantitatively determined using HOMO-LUMO energy separation based on the simple Hückel theory. ${ }^{63}$ The smaller the HOMO-LUMO gap, the more energetically favorable the electrons to add to a highlying LUMO from a low-lying HOMO. The highest occupied molecular orbital (HOMO) and lowest unoccupied molecular orbital (LUMO) of the intermediates Int1 ${ }^{\prime}$ and Int16 are drawn in Fig. 6.

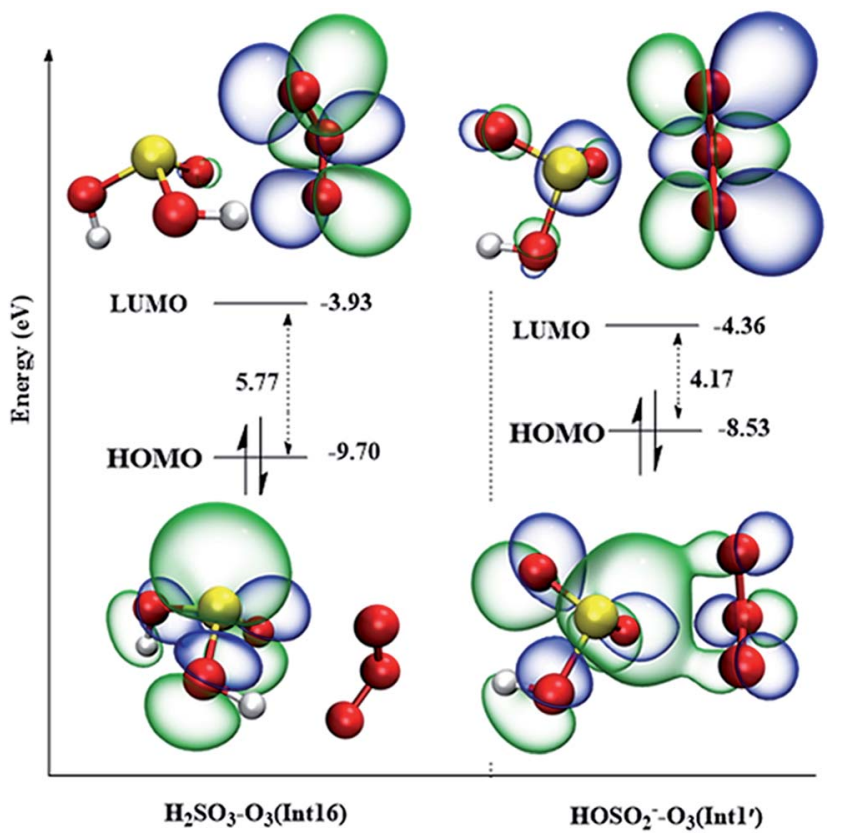

Fig. $6 \mathrm{HOMOs}$ and LUMOs of Int1' $\left(\mathrm{HSO}_{3}{ }^{-}-\mathrm{O}_{3}\right)$ and Int16 $\left(\mathrm{H}_{2} \mathrm{SO}_{3}-\mathrm{O}_{3}\right)$ (isosurfaces $0.03 \mathrm{e} / \AA^{3}$ ).
As can be seen from Fig. 6, for both Int1' and Int16, their HOMOs are mainly occupied on the sulfur atom, and the LUMOs are mainly distributed in the anti-bonding $\pi^{*}$ orbital of $\mathrm{O}_{3}$. The HOMO-LUMO gap in Int1 ${ }^{\prime}(4.17 \mathrm{eV})$ is smaller than that in Int16 $(5.77 \mathrm{eV})$; this indicates that the electrons transfer easily from the HOMO orbital to the LUMO orbital in Int1'. Furthermore, there are some electron distributions in the $\pi^{*}\left(\mathrm{O}^{\prime}\right.$ O) orbital of $\mathrm{O}_{3}$ in Int1 ${ }^{\prime}$ as well as some overlap between the orbital of lone pair electrons in the sulfur atom and the $\pi^{*}(\mathrm{O}-\mathrm{O})$ anti-bonding orbital of $\mathrm{O}_{3}$. The electron distributions in $\pi^{*}(\mathrm{O}-$ $\mathrm{O})$ lead to an increase in the electron population of $\pi^{*}(\mathrm{O}-\mathrm{O})$; this will ultimately facilitate $\mathrm{O}-\mathrm{O}$ bond activation. The $\mathrm{O}-\mathrm{O}$ bond activation can also be reflected by the different $\mathrm{O}-\mathrm{O}$ bond lengths in Int1 ${ }^{\prime}$ and Int16. As shown in Fig. 6 and S2, $\dagger$ the O-O bond lengths of $\mathrm{O}_{3}$ in Int1' are 1.244 and $1.240 \AA$, which are larger than those in Int16 (1.227 and $1.229 \AA$, respectively). Therefore, the smaller HOMO-LUMO gap combined with the electron distributions of $\pi^{*}(\mathrm{O}-\mathrm{O})$ in $\mathrm{O}_{3}$ may be one reason for the lower energy barrier of $\mathbf{T S 1}-\mathbf{P}^{\prime}$ in the $\mathrm{HSO}_{3}{ }^{-}+\mathrm{O}_{3}$ reaction.

\subsection{Kinetics and implication in atmospheric chemistry}

The rate constants for the main pathways of the $\mathrm{H}_{2} \mathrm{SO}_{3} / \mathrm{HSO}_{3}{ }^{-}+$ $\mathrm{O}_{3}$ reactions were calculated in terms of the transition state theory (TST) with the Wigner tunneling correction. There are two competitive reaction pathways for the $\mathrm{H}_{2} \mathrm{SO}_{3}+\mathrm{O}_{3}$ reaction. The reaction pathway reactants $\rightarrow$ Int1 $\rightarrow$ Int $2 \rightarrow \mathbf{P}$ with the total energy barrier of $18.3 \mathrm{kcal} \mathrm{mol}^{-1}$ is the most favorable reaction pathway. The reaction pathway reactants $\rightarrow$ Int14 $\rightarrow \mathbf{P}$ may be a competitive reaction path with the total energy barrier of $19.0 \mathrm{kcal} \mathrm{mol}{ }^{-1}$. Therefore, both reaction pathways were considered. The reaction pathways can be depicted as follows, and the computational details are presented in the ESI.† 


$$
\begin{gathered}
\mathrm{H}_{2} \mathrm{SO}_{3}+\mathrm{O}_{3} \stackrel{k_{1}}{\rightleftharpoons} \operatorname{Int} 1 \stackrel{k_{1-2}}{\longrightarrow} \operatorname{Int} 2 \stackrel{k_{2-\mathrm{P}}}{\longrightarrow} \text { product } \\
\mathrm{H}_{2} \mathrm{SO}_{3}+\mathrm{O}_{3} \stackrel{k_{\mathrm{R}-14}}{\longrightarrow} \operatorname{Int} 14 \stackrel{k_{14-\mathrm{P}}}{\longrightarrow} \text { product } \\
\mathrm{HOSO}_{2}{ }^{-}+\mathrm{O}_{3} \stackrel{k_{1}^{\prime}}{\stackrel{k^{\prime}-1}{\longrightarrow}} \operatorname{Int} 1 \stackrel{k_{1-\mathrm{P}^{\prime}}}{\longrightarrow} \text { product }
\end{gathered}
$$

Considering the atmospheric temperature range from 212 to $298 \mathrm{~K}$ in the troposphere and stratosphere of the Earth, since the altitude changes from $0 \mathrm{~km}$ to $50 \mathrm{~km},{ }^{62}$ the rate constants have been calculated in the temperature range of 200-320 K. The calculated rate constants are presented in Table 1. For the reaction $\mathrm{R} 1$, the rate constants stay within the range of $3.94 \times$ $10^{-31}-8.68 \times 10^{-25} \mathrm{~cm}^{3}$ per molecule per $\mathrm{s}$. The rate constants of reaction $\mathrm{R} 2$ are about 4-5 orders of magnitude smaller than those of reaction R1; this highlights that the oxidation of $\mathrm{H}_{2} \mathrm{SO}_{3}$ by $\mathrm{O}_{3}$ takes place mainly via reaction $\mathrm{R} 1$ within the studied temperature range. The rate constants of $\mathrm{R} 3$ are in the range of $8.89 \times 10^{-11}-1.08 \times 10^{-10} \mathrm{~cm}^{3}$ per molecule per $\mathrm{s}$, which are 15-19 orders of magnitude larger than those of reaction R1. Vahedpour et $a l .{ }^{49}$ previously reported the reaction mechanism and kinetics of the $\mathrm{SO}_{2}+\mathrm{O}_{3}$ reaction. The rate constant of $\mathrm{SO}_{2}+$ $\mathrm{O}_{3}$ is $2.30 \times 10^{-23} \mathrm{~cm}^{3}$ per molecule per $\mathrm{s}$ at room temperature, which is approximately 13 orders of magnitude smaller than that of reaction $\mathrm{R} 3$. Although $\mathrm{SO}_{3}$ produced from the $\mathrm{SO}_{2}+\mathrm{O}_{3}$ reaction can further transform into $\mathrm{H}_{2} \mathrm{SO}_{4}$ via the atmospheric hydrolysis reaction, this reaction plays a minor role in atmospheric sulfate formation. Conversely, $\mathrm{SO}_{2}$ may first hydrolyze to form sulfite in the atmosphere; then, it is easily oxidized to produce sulfate in the presence of $\mathrm{O}_{3}$. This means that sulfite may be a key intermediate in the atmospheric production of sulfate, and $\mathrm{O}_{3}$ is a potentially important oxidant besides $\mathrm{OH}$ for atmospheric sulfate formation.

Speculating that this oxidation reaction is responsible for the atmospheric removal of sulfite species, the atmospheric lifetime $(\tau)$ of sulfite can be estimated by the expression $\tau=\left(k_{\text {tot }}^{\prime} \times\right.$ $\left.\left[\mathrm{O}_{3}\right]\right)^{-1}$ according to the reaction of $\mathrm{HSO}_{3}{ }^{-}+\mathrm{O}_{3}$. When the $\mathrm{O}_{3}$ average concentration is $7.0 \times 10^{11}$ molecule per $\mathrm{cm}^{-3}$ in the atmosphere, ${ }^{64}$ the lifetime of sulfite is estimated to be $0.014 \mathrm{~s}$ at $298 \mathrm{~K}$. This result indicates that once the atmospheric sulfur dioxide transforms into sulfite species, it can be oxidized to sulfate immediately. It has been reported that the production of sulfite from $\mathrm{SO}_{2}$ is almost a barrierless process in atmospheric aerosols in the presence of water, ammonia or atmospheric acids. $^{33,34}$ Consequently, the oxidation of sulfite by $\mathrm{O}_{3}$ may provide a new reaction mechanism for the missing source of atmospheric sulfate.

It is worth mentioning that the concentration of $\mathrm{O}_{3}$ is quite different in the stratosphere. The ozonosphere exits at an altitude of $20-25 \mathrm{~km}$ in the stratosphere, where the $\mathrm{O}_{3}$ concentration reaches its maximum $\left(\sim 2.7 \times 10^{14}\right.$ molecule per $\left.\mathrm{cm}^{-3}\right){ }^{65,66}$ Under this condition, the lifetime of sulfite is estimated to be approximately $4.0 \times 10^{-3} \mathrm{~s}$. Thus, sulfite pollutants reaching the stratosphere may contribute to the destruction of the ozone layer.

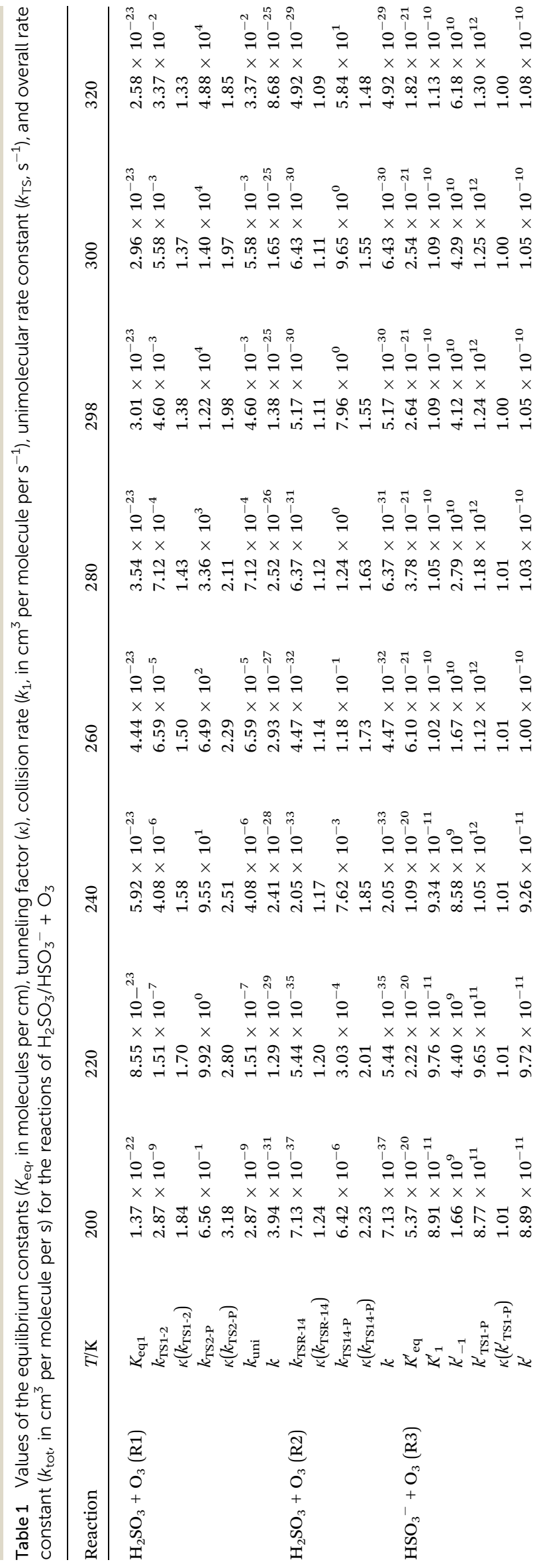




\section{Conclusion}

The reaction mechanism and kinetic investigations on the reaction of $\mathrm{H}_{2} \mathrm{SO}_{3} / \mathrm{HSO}_{3}{ }^{-}+\mathrm{O}_{3}$ were performed theoretically. According to our results, it is clear that the oxidation of $\mathrm{H}_{2} \mathrm{SO}_{3}$ by $\mathrm{O}_{3}$ plays a minor role in the formation of sulfuric acid, and the energy barrier of the favorable reaction channel is $18.3 \mathrm{kcal} \mathrm{mol}{ }^{-1}$. For the oxidation reaction of $\mathrm{HSO}_{3}{ }^{-}+\mathrm{O}_{3}$, the energy barrier of the most feasible pathway is only $0.3 \mathrm{kcal} \mathrm{mol}^{-1}$. In addition, the kinetic analysis verified that the oxidation of $\mathrm{HSO}_{3}{ }^{-}$played an important role in the formation of atmospheric sulfate. Accordingly, in this study, the reaction mechanism of the atmospheric oxidation of tetravalent sulfur species (sulfurous acid/sulfite) to produce hexavalent sulfur species (sulfuric acid/sulfate) was proposed, which might be responsible for the missing source of sulfate and particulate matter in the atmosphere. In the stratosphere with a high concentration of $\mathrm{O}_{3}$, the lifetime of $\mathrm{HSO}_{3}{ }^{-}$decreases to $4.0 \times$ $10^{-3} \mathrm{~s}$; this means that the atmospheric sulfite species may have a potential effect on the destruction of the ozone layer. Our results predict that the sulfite species may be important intermediates in the oxidation of sulfur dioxide to produce sulfate, and $\mathrm{O}_{3}$ is an important potential oxidant besides $\mathrm{OH}$ for the formation of atmospheric sulfate.

\section{Conflicts of interest}

There are no conflicts of interest to declare.

\section{Acknowledgements}

We thank the National Natural Science Foundation of China (Grants 21373098) for providing the financial support. We are grateful to the Computing Center of Jilin Province and High Performance Computing Center of Changchun Normal University for providing essential support.

\section{Notes and references}

1 I. Barnes, J. Hjorth and N. Mihalopoulos, Chem. Rev., 2006, 106, 940-975.

2 A. Mellouki, T. J. Wallington and J. Chen, Chem. Rev., 2015, 115, 3984-4014.

3 R. Zhang, A. Khalizov, L. Wang, M. Hu and W. Xu, Chem. Rev., 2012, 112, 1957-2011.

4 J. G. Calvert, A. Lazrus, G. L. Kok, B. G. Heikes, J. G. Walega, J. Lind and C. A. Cantrell, Nature, 1985, 317, 27-35.

5 B. L. Nie, J. Wang, B. H. Qu, L. X. Sun and S. H. Yan, J. Aerosol Sci., 2017, 114, 169-179.

6 J. W. DePalma, B. R. Bzdek, D. J. Doren and M. V. Johnston, J. Phys. Chem. A, 2012, 116, 1030-1040.

7 R. Y. Zhang, Science, 2010, 328, 1366-1367.

8 R. J. Charlson, S. E. Schwartz, J. M. Hales, R. D. Cess, J. A. Coakley, J. E. Hansen and D. J. Hofmann, Science, 1992, 255, 423-430.

9 J. Chang, D. Y. C. Leung, C. Z. Wu and Z. H. Yuan, Renewable Sustainable Energy Rev., 2003, 7, 453-468.
10 S. Guo, M. Hu, M. L. Zamora, J. Peng, D. Shang, J. Zheng, Z. Du, Z. Wu, M. Shao, L. Zeng, M. J. Molina and R. Zhang, Proc. Natl. Acad. Sci. U. S. A., 2014, 111, 17373-17378.

11 Y. Wang, G. Zhuang, Y. Sun and Z. An, Atmos. Environ., 2006, 40, 6579-6591.

12 H. He, Y. Wang, Q. Ma, J. Ma, B. Chu, D. Ji, G. Tang, C. Liu, H. Zhang and J. Hao, Sci. Rep., 2014, 4, 4172.

13 W. K. Li and M. L. McKee, J. Phys. Chem. A, 1997, 101, 97789782.

14 H. Tachikawa, J. Phys. Chem. A, 2014, 118, 3230-3236.

15 M. Goodarzi, M. Vahedpour and M. Solimannejad, Struct. Chem., 2012, 23, 1609-1615.

16 T. Berndt, T. Jokinen, M. Sipila, R. L. Mauldin III, H. Herrmann, F. Stratmann, H. Junninen and M. Kulmala, Atmos. Environ., 2014, 89, 603-612.

17 G. Sarwar, H. Simon, K. Fahey, R. Mathur, W. S. Goliff and W. R. Stockwell, Atmos. Environ., 2014, 85, 204-214.

18 B. S. Wang and H. Hou, Chem. Phys. Lett., 2005, 410, 235241.

19 I. Kerezsi, G. Lente and I. Fabian, Dalton Trans., 2006, 955960, DOI: 10.1039/b511363f.

20 M.-Y. Nie, C. Gu, K.-L. Zhong and Y.-J. Fang, Energy Fuels, 2012, 26, 5590-5595.

21 J. Zhang, R. Zhang, X. Chen, M. Tong, W. Kang, S. Guo, Y. Zhou and J. Lu, Ind. Eng. Chem. Res., 2014, 53, 6450-6456.

22 H. Meng, Y. Zhu, G. J. Evans, C.-H. Jeong and X. Yao, J. Environ. Sci., 2015, 30, 90-101.

23 T. Kurten, J. R. Lane, S. Jorgensen and H. G. Kjaergaard, J. Phys. Chem. A, 2011, 115, 8669-8681.

24 S. A. Penkett, Nat. Phys. Sci., 1972, 240, 105-106.

25 D. Stone, M. Blitz, L. Daubney, N. U. M. Howes and P. Seakins, Phys. Chem. Chem. Phys., 2014, 16, 1139-1149.

26 L. Vereecken, H. Harder and A. Novelli, Phys. Chem. Chem. Phys., 2012, 14, 14682-14695.

27 R. L. Mauldin III, T. Berndt, M. Sipilae, P. Paasonen, T. Petaja, S. Kim, T. Kurten, F. Stratmann, V. M. Kerminen and M. Kulmala, Nature, 2012, 488, 193-196.

28 J. M. Anglada, G. J. Hoffman, L. V. Slipchenko, M. M. Costa, M. F. Ruiz-Lopez and J. S. Francisco, J. Phys. Chem. A, 2013, 117, 10381-10396.

29 S. M. Kunen, A. L. Lazrus, G. L. Kok and B. G. Heikes, J. Geophys. Res.: Oceans, 1983, 88, 3671-3674.

30 M. Kulmala, T. Petaja, M. Ehn, J. Thornton, M. Sipila, D. R. Worsnop and V. M. Kerminen, in Annual Review of Physical Chemistry, ed. M. A. Johnson and T. J. Martinez, 2014, vol. 65, pp. 21-37.

31 R. Y. Zhang, I. Suh, J. Zhao, D. Zhang, E. C. Fortner, X. X. Tie, L. T. Molina and M. J. Molina, Science, 2004, 304, 1487-1490. 32 Y. F. Cheng, G. J. Zheng, C. Wei, Q. Mu, B. Zheng, Z. B. Wang, M. Gao, Q. Zhang, K. B. He, G. Carmichael, U. Poschl and H. Su, Sci. Adv., 2016, 2, e1601530.

33 J. Liu, S. Fang, W. Liu, M. Wang, F.-M. Tao and J.-y. Liu, J. Phys. Chem. A, 2015, 119, 102-111.

34 J. Liu, S. Fang, Z. Wang, W. Yi, F.-M. Tao and J.-y. Liu, Environ. Sci. Technol., 2015, 49, 13112-13120.

35 G. H. Wang, R. Y. Zhang, M. E. Gomez, L. X. Yang, M. L. Zamora, M. Hu, Y. Lin, J. F. Peng, S. Guo, J. J. Meng, 
J. J. Li, C. L. Cheng, T. F. Hu, Y. Q. Ren, Y. S. Wang, J. Gao, J. J. Cao, Z. S. An, W. J. Zhou, G. H. Li, J. Y. Wang, P. F. Tian, W. Marrero-Ortiz, J. Secrest, Z. F. Du, J. Zheng, D. J. Shang, L. M. Zeng, M. Shao, W. G. Wang, Y. Huang, Y. Wang, Y. J. Zhu, Y. X. Li, J. X. Hu, B. Pan, L. Cai, Y. T. Cheng, Y. M. Ji, F. Zhang, D. Rosenfeld, P. S. Liss, R. A. Duce, C. E. Kolb and M. J. Molina, Proc. Natl. Acad. Sci. U. S. A., 2016, 113, 13630-13635.

36 T. M. Townsend, A. Allanic, C. Noonan and J. R. Sodeau, J. Phys. Chem. A, 2012, 116, 4035-4046.

37 H. Akimoto, in Atmospheric Reaction Chemistry, 2016, pp. 1433, DOI: 10.1007/978-4-431-55870-5.

38 C. R. Hoyle, C. Fuchs, E. Jarvinen, H. Saathoff, A. Dias, I. El Haddad, M. Gysel, S. C. Coburn, J. Trostl, A. K. Bernhammer, F. Bianchi, M. Breitenlechner, J. C. Corbin, J. Craven, N. M. Donahue, J. Duplissy, S. Ehrhart, C. Frege, H. Gordon, N. Hoppel, M. Heinritzi, T. B. Kristensen, U. Molteni, L. Nichman, T. Pinterich, A. S. H. Prevot, M. Simon, J. G. Slowik, G. Steiner, A. Tome, A. L. Vogel, R. Volkamer, A. C. Wagner, R. Wagner, A. S. Wexler, C. Williamson, P. M. Winkler, C. Yan, A. Amorim, J. Dommen, J. Curtius, M. W. Gallagher, R. C. Flagan, A. Hansel, J. Kirkby, M. Kulmala, O. Mohler, F. Stratmann, D. R. Worsnop and U. Baltensperger, Atmos. Chem. Phys., 2016, 16, 1693-1712.

39 I. Faloona, Atmos. Environ., 2009, 43, 2841-2854.

40 C. Brandt and R. Vaneldik, Chem. Rev., 1995, 95, 119-190.

41 A. Simon and K. Waldmann, Z. Anorg. Allg. Chem., 1955, 281, 113-224.

42 A. Simon and K. Waldmann, Z. Anorg. Allg. Chem., 1955, 281, 135-150.

43 A. Simon and K. Waldmann, Z. Anorg. Allg. Chem., 1956, 284, 36-46.

44 A. Simon and K. Waldmann, Z. Anorg. Allg. Chem., 1956, 284, $47-59$.

45 A. Simon, K. Waldmann and E. Steger, Z. Anorg. Allg. Chem., 1956, 288, 131-147.

46 W. A. H. Asman and A. J. Janssen, Atmos. Environ., 1987, 21, 2099-2119.

47 D. Sulzle, M. Verhoeven, J. K. Terlouw and H. Schwarz, Angew. Chem., Int. Ed. Engl., 1988, 27, 1533-1534.

48 R. Atkinson and W. P. L. Carter, Chem. Rev., 1984, 84, 437470.

49 M. Vahedpour, M. Goodarzi, N. Hajari and F. Nazari, Struct. Chem., 2011, 22, 817-822.

50 Y. Zhao and D. G. Truhlar, Theor. Chem. Acc., 2008, 120, 215241.
51 M. J. Frisch, G. W. Trucks, H. B. Schlegel, G. E. Scuseria, M. A. Robb, J. R. Cheeseman, G. Scalmani, V. Barone, B. Mennucci, G. A. Petersson, H. Nakatsuji, M. Caricato, X. Li, H. P. Hratchian, A. F. Izmaylov, J. Bloino, G. Zheng, J. L. Sonnenberg, M. Hada, M. Ehara, K. Toyota, R. Fukuda, J. Hasegawa, M. Ishida, T. Nakajima, Y. Honda, O. Kitao, H. Nakai, T. Vreven, J. A. Montgomery Jr, J. E. Peralta, F. Ogliaro, M. Bearpark, J. J. Heyd, E. Brothers, K. N. Kudin, V. N. Staroverov, T. Keith, R. Kobayashi, J. Normand, K. Raghavachari, A. Rendell, J. C. Burant, S. S. Iyengar, J. Tomasi, M. Cossi, N. Rega, J. M. Millam, M. Klene, J. E. Knox, J. B. Cross, V. Bakken, C. Adamo, J. Jaramillo, R. Gomperts, R. E. Stratmann, O. Yazyev, A. J. Austin, R. Cammi, C. Pomelli, J. W. Ochterski, R. L. Martin, K. Morokuma, V. G. Zakrzewski, G. A. Voth, P. Salvador, J. J. Dannenberg, S. Dapprich, A. D. Daniels, O. Farkas, J. B. Foresman, J. V. Ortiz, J. Cioslowski and D. J. Fox, Gaussian 09, Revision D.01, Gaussian, Inc., Wallingford CT, 2013.

52 L. Liu, X. Zhang, Z. Li, Y. Zhang and M. Ge, Chemosphere, 2017, 186, 430-437.

53 J. Wurmel and J. M. Simmie, J. Phys. Chem. A, 2017, 121, 8053-8060.

54 B. Baidya, M. Lily and A. K. Chandra, Comput. Theor. Chem., 2017, 1119, 1-9.

55 S. R. Hashemi and V. Saheb, Comput. Theor. Chem., 2017, 1119, 59-64.

56 Y. Lan, S. E. Wheeler and K. N. Houk, J. Chem. Theory Comput., 2011, 7, 2104-2111.

57 E. Miliordos and S. S. Xantheas, J. Am. Chem. Soc., 2014, 136, 2808-2817.

58 T. J. Lee and P. R. Taylor, Int. J. Quantum Chem., 1989, 199207, DOI: $10.1002 / q u a .560360824$.

59 J. Peiro-Garcia and I. Nebot-Gil, ChemPhysChem, 2003, 4, 843-847.

60 P. A. Malmqvist and B. O. Roos, Chem. Phys. Lett., 1989, 155, 189-194.

61 H.-J. Werner, P. J. Knowles, G. Knizia, F. R. Manby and M. Schuetz, Wiley Interdiscip. Rev.: Comput. Mol. Sci., 2012, 2, 242-253.

62 M. Torrent-Sucarrat, J. S. Francisco and J. M. Anglada, J. Am. Chem. Soc., 2012, 134, 20632-20644.

63 J. Aihara, J. Phys. Chem. A, 1999, 103, 7487-7495.

64 J. Bai, X. Sun, C. Zhang, C. Gong, J. Hu and J. Zhang, J. Environ. Sci., 2014, 26, 181-188.

65 R. Stolarski, R. Bojkov, L. Bishop, C. Zerefos, J. Staehelin and J. Zawodny, Science, 1992, 256, 342-349.

66 M. Gupta and Abhishek, Indian J. Dent. Sci., 2012, 4, 47-51. 